\title{
Synergistic effect of IL-12 and IL-18 induces TIM3 regulation of $\gamma \delta$ T cell function and decreases the risk of clinical malaria in children living in Papua New Guinea
}

Louis Schofield ${ }^{1,2,3}$, Lisa J. Ioannidis ${ }^{1,3}$, Stephan Karl ${ }^{1,3}$, Leanne J. Robinson 1,3,4,5, Qiao Y. Tan 1,3, Daniel P. Poole ${ }^{6,7}$, Inoni Betuela ${ }^{4}$, Danika L. Hill ${ }^{1,3}$, Peter M. Siba ${ }^{4,8}$, Diana S. Hansen ${ }^{1,3}$, Ivo Mueller ${ }^{1,3}$ and Emily M. Eriksson ${ }^{1,3,9^{*}}$

\begin{abstract}
Background: $\gamma \delta$ T cells are important for both protective immunity and immunopathogenesis during malaria infection. However, the immunological processes determining beneficial or detrimental effects on disease outcome remain elusive. The aim of this study was to examine expression and regulatory effect of the inhibitory receptor T-cell immunoglobulin domain and mucin domain 3 (TIM3) on $\gamma \delta$ T cells. While TIM3 expression and function on conventional a $\beta$ T cells have been clearly defined, the equivalent characterization on $\gamma \delta \mathrm{T}$ cells and associations with disease outcomes is limited. This study investigated the functional capacity of TIM3 $+\gamma \delta$ T cells and the underlying mechanisms contributing to TIM3 upregulation and established an association with malaria disease outcomes.

Methods: We analyzed TIM3 expression on $\gamma \delta T$ cells in 132 children aged 5-10 years living in malaria endemic areas of Papua New Guinea. TIM3 upregulation and effector functions of TIM3 $+\gamma \delta$ T cells were assessed following in vitro stimulation with parasite-infected erythrocytes, phosphoantigen and/or cytokines. Associations between the proportion of TIM3-expressing cells and the molecular force of infection were tested using negative binomial regression and in a Cox proportional hazards model for time to first clinical episode. Multivariable analyses to determine the association of TIM3 and IL-18 levels were conducted using general linear models. Malaria infection mouse models were utilized to experimentally investigate the relationship between repeated exposure and TIM3 upregulation.

Results: This study demonstrates that even in the absence of an active malaria infection, children of malaria endemic areas have an atypical population of TIM3-expressing $\gamma \delta$ T cells (mean frequency TIM3+ of total $\gamma \delta$ T cells $15.2 \% \pm 12$ ). Crucial factors required for $\gamma \delta$ T cell TIM3 upregulation include IL-12/IL-18, and plasma IL-18 was associated with TIM3 expression $(P=0.002$ ). Additionally, we show a relationship between TIM3 expression and infection with distinct parasite clones during repeated exposure. TIM $3+\gamma \delta T$ cells were functionally impaired and were associated with asymptomatic malaria infection (hazard ratio $0.54, P=0.032$ ).

Conclusions: Collectively our data demonstrate a novel role for IL-12//L-18 in shaping the innate immune response and provide fundamental insight into aspects of $\gamma \delta \mathrm{T}$ cell immunoregulation. Furthermore, we show that TIM3 represents an important $\gamma \delta T$ cell regulatory component involved in minimizing malaria symptoms.
\end{abstract}

Keywords: $\gamma \delta$ T cells, TIM3, IL-12, LL-18, Malaria, Plasmodium

\footnotetext{
* Correspondence: eriksson@wehi.edu.au

${ }^{1}$ Walter and Eliza Hall Institute of Medical Research, Division of Population

Health and Immunity, Melbourne, VIC 3052, Australia

${ }^{3}$ Department of Medical Biology, The University of Melbourne, Melbourne,

VIC 3052, Australia

Full list of author information is available at the end of the article
} 


\section{Background}

Immunoregulation is an essential part of the immune response and ensures that a comprehensive and protective response is elicited, but with limited damage to the host. Immunoregulation can be achieved by check-point proteins that either enhance or inhibit cell reactivity [1]. Inappropriate expression of these proteins can therefore have detrimental consequences for immune responses to infection and also affect pathogenesis. Thus, blocking of check-point proteins to restore functional capacity of effector cells has been explored as potential immunotherapy for chronic viral infections and cancers [2-8]. The expression of immunoregulatory proteins on conventional $\mathrm{T}$ cells has been recently shown in both malaria rodent infection models and in malaria-infected individuals, where inhibitory therapies of immunoregulatory proteins resulted in enhanced parasite clearance [9-13]. However, the effect of continuous malaria exposure on immunoregulation among the innate cell compartment remains a critically under-investigated aspect of malaria immunology.

$\gamma \delta \mathrm{T}$ cells are a subset of $\mathrm{T}$ cells that express a distinct $\mathrm{T}$ cell receptor (TCR). These cells are considered to be part of the innate/intermediate immune system due to their ability to respond rapidly to non-peptide antigens without the requirement of major histocompatibility complex (MHC) presentation. Substantial evidence indicates that $\gamma \delta$ T cells mediate essential protection against a number of pathogens including Plasmodium [14-19] where Plasmodium stimulation of $\gamma \delta \mathrm{T}$ cells involves metabolites of the 1-deoxy-D-xylulose 5-phosphate (DOXP) pathway [20]. While immunity to malaria requires a multifaceted network of cell interactions and cytokine production involving both innate and adaptive immune responses, $\gamma \delta \mathrm{T}$ cells have been shown to contribute to key processes associated with beneficial outcomes $[21,22]$. Mouse studies demonstrate that the frequency of $\gamma \delta \mathrm{T}$ cells is significantly increased during malaria infection and they provide protective immunity via interferon gamma (IFN- $\gamma$ ) production and control of parasitemia $[21,23,24]$. Similarly, $\gamma \delta \mathrm{T}$ cells are an important early source of IFN- $\gamma$ in malaria-infected individuals, which is associated with reduced risk of clinical disease [25-30]. Furthermore, inhibition of intracellular parasite growth and granulysin-dependent cytotoxic activity against released blood stage merozoites have been demonstrated [14, 31-33]. However, in addition to a protective role during malaria, $\gamma \delta \mathrm{T}$ cells were also suggested to contribute to pathogenesis. This is supported by observations that depletion of $\gamma \delta \mathrm{T}$ cells protected mice from developing cerebral malaria in a $P$. berghei ANKA mouse model [34] and that $\gamma \delta$ T cells were found to be one of the predominant sources of cytokines and chemokines associated with severe malaria in malaria- infected individuals [29]. Although numerous studies describe activation of $\gamma \delta$ T cells in response to malaria, the understanding of how these cells are regulated is remarkably limited.

T-cell immunoglobulin domain and mucin domain 3 (TIM3) is a relatively recently described immunoregulatory protein that belongs to the TIM protein family. In humans this family consists of TIM1, TIM3, and TIM4, whereas mice have an additional protein, TIM2 [35-38]. TIM3 is expressed by T cells, dendritic cells (DCs), natural killer (NK) cells, and monocytes and interacts with galectin-9 [39]. TIM3 is generally referred to as a negative regulator, but TIM3 expression can affect different functions in the innate and the adaptive immune system and on different cells. In mice, engagement of TIM3 on conventional $\alpha \beta \mathrm{T}$ cells results in apoptosis and loss of effector T cells [39], whereas TIM3 expression on human $\mathrm{T}$ cells is associated with functional exhaustion [4, 39-41]. In contrast, TIM3 is thought to be a maturation marker on human NK cells [42] and is also abundantly expressed on monocytes regulating cytokine production in these cells $[43,44]$. Recently TIM3 was observed to be upregulated in mice during acute Plasmodium infection $[13,45]$. TIM3 was found to be expressed by conventional $\mathrm{T}$ cells and NK cells, and in vivo blocking of TIM3 resulted in enhanced parasite clearance [13]. Furthermore, TIM3-expressing CD4+ and CD $8+\alpha \beta$ T cells were observed in individuals during acute $P$. vivax infection but were undetectable following treatment [46].

In contrast, the effect of TIM3 expression on $\gamma \delta$ T cells has only recently started to receive attention [47, 48]. In malaria, the biological relevance of TIM3 expression on $\gamma \delta$ $\mathrm{T}$ cell function for clinical outcomes has not previously been investigated. Recent findings suggest that dysfunctional V82 $\gamma \delta$ T cells associated with malaria exposure induce tolerance to the Plasmodium parasite [47]. However, the precise immunological processes responsible for $\gamma \delta \mathrm{T}$ cell dysregulation remain elusive. Here, we specifically investigated associations between TIM3 and $\gamma \delta$ T cell function during malaria as well as the factors that govern TIM3 upregulation. The roles TIM3 expression plays in the control of pathogenic mechanisms were also explored. Our main findings revealed that interleukin (IL)-12 in synergy with IL-18 are key factors required for TIM3 induction. Moreover, TIM3 expression renders cells functionally impaired, which is associated with reduced risk of clinical malaria. These findings provide novel insights into immune-specific processes involved in $\gamma \delta$ T cell regulation and represent a major advancement in the field of $\gamma \delta$ T cell biology.

\section{Methods}

Study site and subjects

Human blood samples from children aged 5-10 years were collected in a clinical trial (ClinicalTrials.gov registration: 
NCT02143934) conducted in 2009 and 2010 in five villages in East Sepik Province of Papua New Guinea (PNG), where both $P$. falciparum and $P$. vivax are endemic [49]. Children were randomized into two treatment groups of directly observed treatment (DOT) over a total of 27 days. The first group of children received chloroquine $(\mathrm{CQ}$, days $1-3$ of DOT), artemether-lumefantrine (Coartem ${ }^{\circ}$ (AL, days 1113 of DOT), and primaquine (PQ, days $1-20$ of DOT; $0.5 \mathrm{mg} / \mathrm{kg}$ per dose). The second group of children received CQ (days 1-3 of DOT), AL (days 11-13 of DOT), and a placebo (days 1-20 of DOT). The drug treatment was implemented to be able to quantify the contribution of $P$. vivax and $P$. ovale relapses to infection and disease during follow-up in an epidemiological study of the cohort [49]. The first treatment regime was designed to clear all parasites including $P$. vivax hypnozoite stages, whereas the second treatment regime cleared only blood stages. Venous bleeds and peripheral blood mononuclear cell (PBMC) isolation were performed following completion of drug treatment, and PBMCs were cryopreserved.

Children were actively followed for 8 months with finger-prick (250- $\mu \mathrm{l})$ blood samples collected every 2 weeks for the first 12 weeks and every 4 weeks for the remainder of the follow-up period. In addition passive surveillance measures were implemented at local health centers, aid posts, and via the village health volunteer network. Febrile children were tested with a rapid diagnostic test (RDT), and a blood slide was collected. Symptomatic infections (those with fever and who tested positive by RDT and/or light microscopy) during followup were treated with AL. For RDT-negative children, the slides were read within $12 \mathrm{~h}$. If the slides were positive, the children were treated the next day. If the slide was negative, the result was recorded but no further action taken. The collected blood samples were screened for infection with Plasmodium spp. by light microscopy and quantitative real-time PCR (qPCR). Slides were scored as light microscopy-positive for an individual Plasmodium species if the species was detected independently by at least two microscopists and/or if subsequent qPCR diagnosis confirmed the presence of the species. Slide discrepancies were adjudicated by a World Health Organization (WHO)-certified level 1 (expert) microscopist [49]. A generic qPCR was used to detect all Plasmodium species occurring in PNG, followed by subsequent species-specific qPCRs on Plasmodium-positive samples [50, 51].

A subset of PBMC samples from the children enrolled in the clinical trial $(n=132$, of which $n=63$ belonged to the primaquine drug-treated group and $n=69$ belonged to the placebo group) were included in the current study. These children all had at least one Plasmodium falciparum infection verified by PCR during follow-up to ensure ongoing exposure. Of these, 50 individuals had a clinical episode during follow-up. A clinical episode of malaria was defined as febrile illness (axillary temperature of $\geq 37.5^{\circ} \mathrm{C}$, current or previous $48 \mathrm{~h}$ ) plus the presence of $P$. vivax or $P$. falciparum parasites (any density) by light microscopy. PBMCs collected from 20 healthy blood donors by the Australian Red Cross were used as controls.

\section{Mouse infections}

Female C57BL/6 mice aged 6-8 weeks were infected with $5 \times 10^{4}$ Plasmodium chabaudi-infected red blood cells (iRBCs) intravenously or with $1 \times 10^{6} P$. berghei ANKA iRBCs intraperitoneally. $P$. chabaudi-infected mice were drug-treated on day 14 post-infection with CQ $(6 \mu \mathrm{g} / \mathrm{ml})$ and pyrimethamine $(70 \mu \mathrm{g} / \mathrm{ml})$-containing water for 5 days. Drug treatment on day 14 coincided with control of the infection and allowed for a whole infection cycle to be completed before drug treatment. $P$. berghei-infected mice were treated at day 5 post-infection to avoid progression to cerebral malaria. Drug treatment consisted of an intraperitoneal injection of CQ $(10 \mathrm{mg} / \mathrm{kg})$ and pyrimethamine $(10 \mathrm{mg} / \mathrm{kg})$ followed by CQ- and pyrimethamine-containing water for 5 days as described previously [52]. Livers and spleens were removed at different time points following completion of drug treatment. Untreated $P$. chabaudi-infected mice establish a submicroscopic chronic infection with intermittent detectable parasitemia peaks. Mice that were chronically infected with $P$. chabaudi were left untreated until day 98 after the initial infection. Mice infected multiple times (three consecutive infections ( $P$. chabaudi only) or two consecutive infections ( $P$. chabaudi and $P$. berghei)) were drug-treated and then re-infected on day 14 postcompletion of drug treatment to allow the immune cells to return to steady state (Additional file 1: Figure S1).

\section{Parasite lines and cultures}

Parasite lines 3D7 and XIE were cultured in human red blood cells, and trophozoite-stage parasites were isolated as described previously $[29,53]$. XIE parasites were snap frozen in $15 \%$ glycerol in phosphate-buffered saline (PBS) and thawed by sequential addition of $12 \%, 1.8 \%$, and $0.9 \% \mathrm{NaCl}$ and subsequently used for stimulation of cohort samples.

\section{Flow cytometry}

PBMCs $\left(5 \times 10^{5}\right)$ were stained with antibody cocktails in FACS buffer (PBS containing $0.5 \%$ bovine serum albumin and $2 \mathrm{mM}$ ethylenediaminetetraacetic acid) on ice for $30 \mathrm{~min}$. The human antibodies used were fluorescein isothiocyanate (FITC)-conjugated anti- $\gamma \delta T C R$ (clone 11 F2, BD Biosciences, San Jose, CA, USA), Qdot 605-conjugated anti-CD27-, Qdot 655-conjugated Streptavidin (Invitrogen, Carlsbad, CA, USA), PE-Texas Red (ECD)-conjugated anti-CD3 (clone UCHT1, Beckman Coulter, Brea, CA, USA), Brilliant Violet 421-conjugated anti-CD16-(clone 3G8), Brilliant Violet 711-conjugated 
anti-CD45RA (clone HI100, both from Biolegend, San Diego, CA, USA), and phycoerythrin (PE)-conjugated antiTIM3 (clone FAB2365P from R\&D Systems Minneapolis, $\mathrm{MN}$, USA). The mouse antibodies used were FITCcomjugated anti-CD3 (clone 145-2C11), PE-conjugated anti-TIM3 (clone RMT3-23), and PerCPCy5.5-conjugated anti- $\gamma \delta$ TCR (clone GL3, all from Biolegend). Aqua amine reactive dye (Invitrogen) was used for dead cell exclusion. Samples were analyzed on a four-laser Fortessa flow cytometer (BD Biosciences). Data analysis was performed using FlowJo software (Tree Star, Ashland, OR, USA). Boolean gating was utilized to evaluate multiparametric expression, and fluorescence minus one (FMO) controls were used to set gates. The gating strategy is illustrated in Additional file 2: Figure S2.

\section{Intracellular cytokine staining}

PBMCs $\left(2 \times 10^{5}\right.$ cells/well in triplicate) were stimulated with either uninfected RBCs (uRBCs) or iRBCs $\left(6 \times 10^{5}\right.$ / well) for $24 \mathrm{~h}$ or isopentenyl pyrophosphate (IPP, $3 \mu \mathrm{M}$, Sigma-Aldrich, St Louis, MO, USA) for $16 \mathrm{~h}$. Brefeldin A $(10 \mu \mathrm{g} / \mathrm{ml}$, Sigma-Aldrich) and monensin (BD Biosciences) were added to the cells for the last $8 \mathrm{~h}$ of incubation. Assessment of $\gamma \delta \mathrm{T}$ cell cytokine production was performed by intracellular cytokine staining using allophycocyanin (APC)-conjugated anti-IFN- $\gamma$ (clone B27, BD Biosciences) and PE-Cy7-conjugated anti-tumor necrosis factor alpha (TNF- $\alpha$ ) (clone MAb11, eBioscience, San Diego, CA, USA), and cytotoxic capacity was assessed by Brilliant Violet 421-conjugated anti-CD107a (clone $\mathrm{H} 4 \mathrm{~A} 3$, Biolegend) staining in culture. A positive response was determined as the frequency of responding cells, which was twice above background and was $\geq 0.1 \%$ IFN- $\gamma$, TNF- $\alpha$, or CD107a-positive $\gamma \delta$ T cells of all $\gamma \delta \mathrm{T}$ cells or $\geq 0.5 \%$ positive $\gamma \delta$ T cells of $\gamma \delta$ T cell subsets following subtraction of background.

\section{Cytokine and antigen stimulation of PBMCs}

PBMCs $\left(5 \times 10^{5}\right.$ cells $)$ from healthy individuals were stimulated with the following conditions: IL-6 (10 ng/ $\mathrm{ml}), \mathrm{IFN}-\gamma$ (10 ng/ml), IL-12/IL-18 (50 ng/ml each), IL-4 (10 $\mathrm{ng} / \mathrm{ml}), \mathrm{IL}-1 \beta(1 \mathrm{ng} / \mathrm{ml}$, all from Peprotech, NJ), TNF- $\alpha$ (10 ng/ml, Life Technologies, Carlsbad, CA, USA), iRBCs (3 iRBCs: 1 PBMC), lipopolysaccharide (LPS, $1 \mathrm{ug} / \mathrm{ml}$, InvivoGen, San Diego, CA, USA), IPP $(3 \mu \mathrm{M})$, or cells in medium only. After $24 \mathrm{~h}$ of incubation, the frequency of TIM $3+\gamma \delta$ T cells was assessed by flow cytometry.

\section{Enzyme-linked immunosorbent assay (ELISA)}

Plasma was assessed for IL-12p70 and IL-18 cytokine levels using ELISA (RayBiotech, Norcross, GA, USA) according to the manufacturer's instructions. Plasma from healthy controls were included as negative controls for
IL-12 and to measure the baseline plasma IL-18 concentration of healthy individuals.

\section{Statistical analysis}

Statistical analyses were performed using Prism 6.0 (GraphPad software) and STATA 12. Flow cytometry data were analyzed using the Student's $t$ test or KruskalWallis test followed by the Dunn post-test as indicated. Correlation coefficients were determined by Spearman rank correlation. Logistic regression was used to test whether recent infection was associated with an increased proportion of TIM $3+\gamma \delta \mathrm{T}$ cells and whether TIM3 expression varied the odds of experiencing a clinical malaria episode during the follow-up period. Associ-

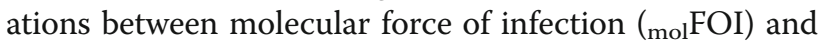
the proportion of TIM3-expressing cells were tested using negative binomial regression and in a Cox proportional hazards model for time to first clinical episode. In order to normalize the TIM3 expression levels, the data were power transformed. Clinical incidence was defined as the frequency of occurrence per time at risk of infections associated with a fever. molFOI was determined by genotyping all samples for merozoite surface protein 2 (msp2) using capillary electrophoresis for fragment sizing $[54,55]$ in addition to using PCR conditions for highly purified DNA [56]. molFOI was defined as the frequency of acquisition of new malaria infections per time at risk [55]. New infections were defined as those where the detected allele had not been observed in a child at the previous two active or passive case detection visits [49]. Time at risk was adjusted for missed visits, and children were censored from the analysis after they missed three or more active case detection visits. Multivariable analyses to determine the association of TIM3 levels and relevant covariates, including IL-18 levels, were conducted using general linear models (GLMs). Backwards elimination was applied to construct the most parsimonious model.

\section{Results \\ TIM3 expression is upregulated on $\gamma \delta \mathrm{T}$ cells following acute infection}

TIM3 expression is present on the surface of activated $\alpha \beta \mathrm{T}$ cells following stimulation and acts as a negative regulator [4, 39-41]. Recently TIM3 expression on conventional $\mathrm{T}$ cells was demonstrated to be upregulated during acute Plasmodium infection in both mice and humans $[13,46]$. In contrast, little is known about TIM3 expression on $\gamma \delta$ T cells and whether Plasmodium infection is associated with $\gamma \delta$ T cell TIM3 expression. It is also not established whether TIM $3+\gamma \delta$ T cells remain detectable even in the absence of an active infection or whether chronic infection is required. Prolonged expression of negative regulators such as TIM3 may affect responses to subsequent infections. This may be especially 
important in settings where an individual is repeatedly infected with a pathogen, such as in malaria endemic areas. To address these questions, we examined TIM3 expression on $\gamma \delta \mathrm{T}$ cells following acute malaria infection. To that end, C57BL/6 mice were infected with $P$. chabaudi iRBCs, and 14 days postinfection, mice were drug-treated to resolve infection completely. Cells were isolated from the liver and spleen at different time points (0-14 days) following completion of drug treatment, and $\gamma \delta \mathrm{T}$ cells were subsequently assessed for TIM3 expression (Fig. 1a and $\mathrm{b}$ ). We found that the frequency of TIM $3+\gamma \delta \mathrm{T}$ cells was significantly increased in both liver (mean $9.69 \pm 1.01$ ) and spleen (mean $36.9 \pm 5.66$ ) immediately following resolution of acute infection compared to naive mice (liver: $2.66 \pm 1.25$ and spleen: $2.84 \pm 0.45$ ). The presence of these cells remained significantly increased in the spleen for up to 14 days (mean $3.61 \pm$ 0.33 , Fig. $1 \mathrm{~b}$ ), whereas TIM3 expression by hepatic $\gamma \delta$ $\mathrm{T}$ cells returned back to background levels by day 3 post-completion of drug treatment (mean $1.77 \pm 0.53$, Fig. 1a). Similarly, the total number of TIM3 $+\gamma \delta \mathrm{T}$ cells in the spleen significantly increased from day 0 after drug treatment (mean $9.5 \times 10^{5} \pm 2.7 \times 10^{5}$ cells, Fig. 1d) compared to naive mice (mean $1.8 \times 10^{4} \pm$ $6.3 \times 10^{3}$ cells) and remained significantly increased until the last measured time point at day 14. However, the total number of all $\gamma \delta \mathrm{T}$ cells in the spleen at day 0 was not significantly different from that of naive mice (Fig. 1f). In contrast, the number of TIM3+ $\gamma \delta \mathrm{T}$ cells and the total number of all $\gamma \delta$ T cells in the liver were not significantly increased compared to naive mice, apart from day 3 when a small increase in the number of TIM3 $+\gamma \delta$ T cells was observed (Fig. 1c and e). To determine whether a TIM $3+\gamma \delta$ T cell population was persistently detectable in untreated, chronically $P$. chabaudiinfected mice, $\gamma \delta$ T cells from these mice were assessed on day 98 p.i (Fig. $1 \mathrm{~g}$ and $\mathrm{h}$ ). We found that TIM $3+\gamma \delta$ T cells were present in both liver and spleen at a significantly higher frequency compared to naive mice $(P=0.0002$ and $P=0.0006$ respectively). An outlier, which had a high frequency of TIM $3+\gamma \delta \mathrm{T}$ cells in both organs, was observed. Although at the time of analysis parasitemia was submicroscopic in this mouse, a recent recurrence of parasitemia is likely to have occurred. The difference in frequency of TIM $3+\gamma \delta$ T cells between the remaining chronically infected mice compared to naive mice remained significant when the outlier was excluded from the analysis $(P=0.0003$ and $P=0.0012$ respectively). This demonstrates that acute malaria infection induces $\gamma \delta$ T cell TIM3 expression, and a population of TIM $3+\gamma \delta$ T cells is continually detectable both during chronic infection and following resolution of infection.
The frequency of TIM3+ $\gamma \delta \mathrm{T}$ cells is increased in children living in malaria endemic areas

TIM3 expression is commonly absent on $\gamma \delta$ T cells during steady state. However, we show that TIM3 expression is induced in Plasmodium-infected mice. To extend these observations to human malaria, TIM3 expression was examined on $\gamma \delta$ T cells from PBMC isolated from drug-treated children residing in malaria endemic areas in PNG $(n=132)$. We found that despite the absence of active malaria infection, all PNG children exhibited significantly higher proportions of TIM $3+\gamma \delta$ T cells compared to healthy controls (HC) (Fig. 2a). In addition, children who had experienced a recent infection at enrollment (28-30 days prior to PBMC collection) had a significantly increased frequency of TIM3-expressing $\gamma \delta$ $\mathrm{T}$ cells compared to children who were malaria free at enrollment $(P \leq 0.001)$. In contrast, no expression of PD1 was observed on $\gamma \delta$ T cells, but it was expressed at low frequencies on $\mathrm{CD} 3+\gamma \delta \mathrm{TCR}-$ cells (Additional file 3: Figure S3). This indicates that malaria exposure induces TIM3 expression, which is maintained for a considerable duration even in the absence of new infections.

To assess whether the infective Plasmodium species affected TIM3 expression, we compared the frequency of TIM $3+\gamma \delta$ T cells between children who were infected with $P$. vivax or $P$. falciparum at enrollment or had a co-infection of $P$. vivax, $P$ falciparum, $P$. ovale, or $P$. malariae with a minimum of two species present. We found that TIM $3+\gamma \delta \mathrm{T}$ cell was significantly increased in children with either $P$. falciparum single infections $(P \leq 0.05)$ or co-infections $(P \leq 0.01)$ compared to $P$. vivax infections alone (Fig. 2b). This suggests that infections with different species result in dissimilar TIM3 expression profiles.

$\gamma \delta \mathrm{T}$ cells are present in the periphery in a "pre-activated" state and can be divided into subsets based on expression of surface markers CD27 and CD45RA [57-60]. To assess which subsets of $\gamma \delta$ T cells expressed TIM3, we distinguished between naive $(\mathrm{CD} 27+\mathrm{CD} 45 \mathrm{RA}+)$, central memory (TCM; CD27+CD45RA-), effector memory (TEM; CD27- CD45RA-), and terminally differentiated effector memory (TEMRA; CD27- CD45RA + ) $\gamma \delta$ T cells (Fig. 2c, Additional file 2: Figure S2). We found that TIM3 was predominantly expressed on TEMRA $\gamma \delta$ T cells. A subset of TEMRA cells have previously been found to express the low affinity FC receptor CD16 which defines a functionally discrete effector population, with high cytokine and cytotoxic capacity [61]. To determine the extent of TIM3 and CD16 co-expression, additional phenotypic analysis of the TEMRA subset was performed. We found that the majority of TIM3 expression was present on CD16+ TEMRA $\gamma \delta$ T cells (Fig. 2d, Additional file 2: Figure S2). This demonstrates that TIM3 is primarily expressed by a memory $\gamma \delta$ T cell population with specific function. 
a

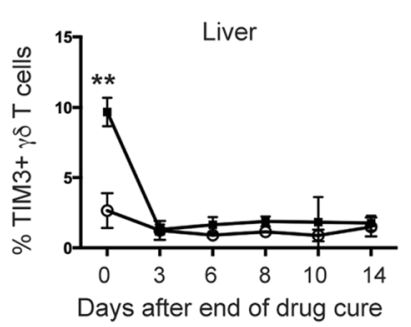

C

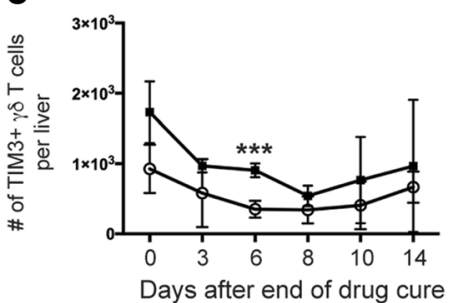

e

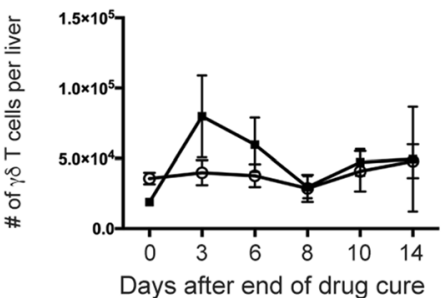

g

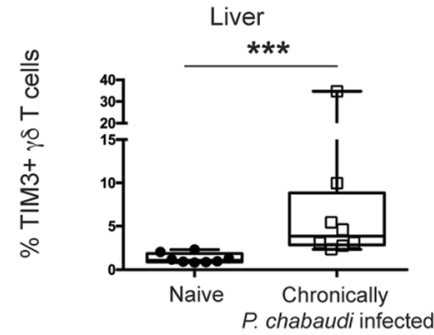

b

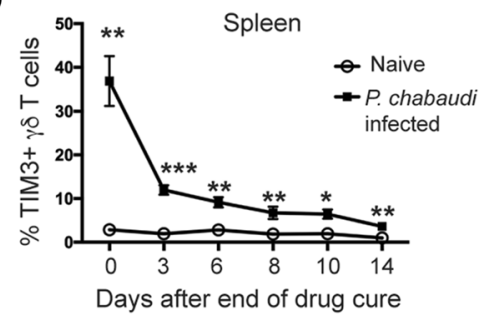

d

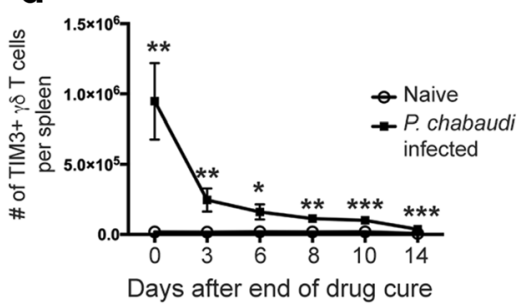

f

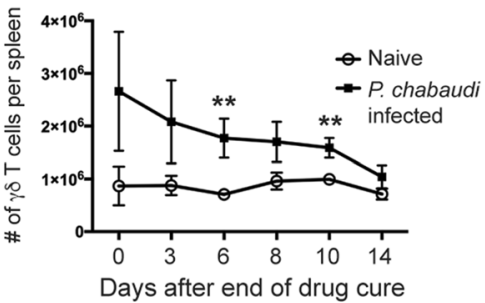

h

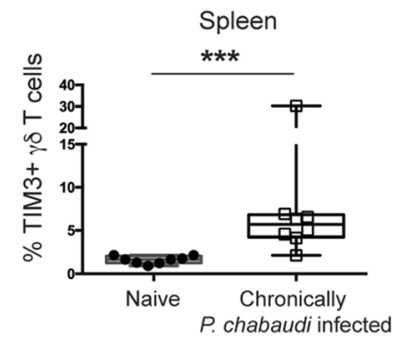

Fig. 1 TIM3 expression is maintained on $\gamma \delta$ T cells after drug treatment and parasite clearance. C57BL/6 mice were infected with $P$. chabaudi and then drug-treated with chloroquine and pyrimethamine. (a) Liver lymphocytes and (b) splenocytes were stained for TIM3 expression at different time points following end of drug cure to assess the percentage of TIM $3+\gamma \delta$ T cells, (c) and (d) number of TIM3 $+\gamma \delta$ T cells, and (e) and (f) the total number of $\gamma \delta T$ cells in the liver and spleen. The data represent three mice per time point and shows mean \pm standard deviation (SD). Chronically $P$. chabaudi-infected mice $(n=8)$ were assessed on day 98 post-infection for TIM3 $+\gamma \delta$ T cells in the $(\mathbf{g})$ liver and $(\mathbf{h})$ spleen. The data represent two independent experiments. Statistical analysis was performed using (a-f) paired $t$ tests with Holm-Sidak method or $(\mathbf{g})$ and $(\mathbf{h})$ Student's $t$ test. ${ }^{*} P<0.05,{ }^{* *} P<0.01,{ }^{* * *} P<0.001$

\section{$\gamma \delta \mathrm{T}$ cell TIM3 expression is associated with exposure to}

\section{distinct parasite species and clones}

We have shown that TIM3 expression differs in children infected with different Plasmodium species (Fig. 2b). To better understand the relationship between malaria exposure and TIM3 expression levels, the incidence of new clones acquired by each child during the follow-up period $\left({ }_{\text {mol }} \mathrm{FOI}\right)$ was tested for association with TIM3. We found that expression levels on CD16+ TEMRA $\gamma \delta$ $\mathrm{T}$ cells specifically were found to be significantly associated with ${ }_{\text {mol }}$ FOI for $P$. falciparum (Table 1 and Additional file 4: Table S1, adjusted incidence rate ratio (IRR): $1.40,95 \%$ confidence interval (CI): 1.04-1.88, $P=$
0.027), for each increment of power transformed TIM3 expression after adjusting for potential confounders: age, sex, treatment arm, infection status at enrollment, and hemoglobin level. No significant association was found with ${ }_{\text {mol }}$ FOI for $P$. vivax. This suggests that in endemic areas, exposure to diverse parasites is a contributing factor for TIM3 upregulation in innate cells.

To test the effect of consecutive infections with the same Plasmodium species or different species on TIM3 expression experimentally, a mouse infection model was used where C57BL/6 mice were repeatedly infected with $P$. chabaudi or $P$. berghei with drug treatment between infections. Livers and spleens were removed on day 7 after 

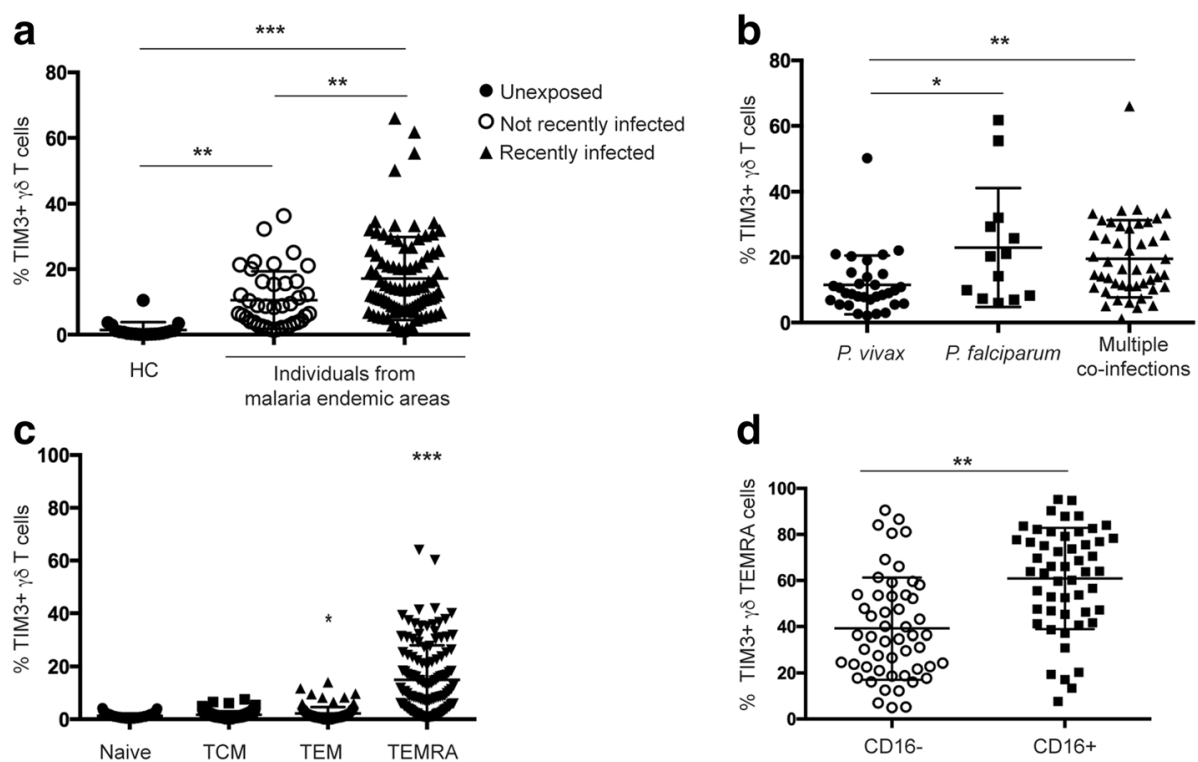

Fig. $2 \gamma \delta$ T cell TIM3 expression in individuals from malaria endemic areas is increased compared to healthy controls (HC). PBMCs from individuals living in malaria endemic areas recently infected in the last 30 days, not recently infected, and healthy controls $(\mathrm{HC})$ were surface stained for TIM3 expression. a Frequency of $\gamma \delta$ T cells expressing TIM3 (recently infected, filled triangles, $n=92$; not recently infected, open circles, $n=40 ;$ and healthy controls, filled circles, $n=20)$. b Percentage of $\gamma \delta$ T cells expressing TIM3 in individuals recently infected with either $P$. vivax only (filled circles; $n=32), P$. falciparum only (filled squares; $n=13$ ), or co-infected with multiple species (P. vivax, P. falciparum, $P$. ovale, and $P$. malariae) (filled triangles; $n=47)$. c Frequency of TIM3 $+\gamma \delta T$ cell subsets distinguished by expression of CD27 and CD45RA (TCM central memory T cell, TEM effector memory T cell, TEMRA terminally differentiated effector memory T cell). $\mathbf{d}$ Frequency of TIM3-expressing CD16+ (open circles) and CD16- (squares) TEMRA $\gamma \delta$ T cells (mean \pm SD). Statistical analysis was performed using $(\mathbf{a}-\mathbf{c})$ Kruskal-Wallis tests with Dunn's post-test; $\mathbf{c}$ multiple comparison to naive, and (d) paired Student's $t$ tests. ${ }^{*} P<$ $0.05,{ }^{* *} P<0.01,{ }^{* * *} P<0.001$

completion of the final round of drug treatment and assessed for TIM $3+\gamma \delta \mathrm{T}$ cells (Additional file 1: Figure $\mathrm{S} 1 \mathrm{~A}$ ). We found that mice repeatedly infected (three infections) with the same species (multiple $P$. chabaudi) did not have an increased frequency of TIM $3+\gamma \delta$ T cells in the spleen or in the liver (Fig. $3 \mathrm{a}$ and $\mathrm{b}$ ) compared to naive mice. Control groups of mice received a single infection of $P$. chabaudi and were either drug-treated on day 14 (P. chabaudi day 7) or day 98 post-infection (P. chabaudi day 98, Additional file 1: Figure S1C) and then assessed for TIM $3+\gamma \delta$ T cells 7 days post-drug treatment. Consistent with Fig. 1a and b, TIM3 $+\gamma \delta$ T cells were observed in the spleens of $P$. chabaudi day 7 mice, but not in the liver. To investigate if multiple infections with different species had an effect on TIM3 expression, we infected mice with $P$. chabaudi followed by drug treatment and then $P$. berghei infection (P. chabaudi $+P$. berghei) or vice versa (P. berghei $+P$. chabaudi) (Additional file 1: Figure S1B and Fig. 3c and d). In contrast to mice exposed multiple times to a single malaria species, mice infected sequentially with different species had an increased proportion of TIM $3+\gamma \delta$ T cells in both the spleen and liver compared to naive mice $(P \leq 0.05$ and $P \leq 0.05$ respectively). TIM $3+\gamma \delta$ T cells were also observed following a single infection of $P$. berghei at day 7 post-drug treatment completion. Collectively, these observations show that TIM3 is induced following a single infection, but not by sequential infections with the same species and clones. However, consecutive infections with different species or different clones from the same species (as indicated in Table 1) contribute to TIM3 expression in innate cells during repeated exposures.

TIM3 $+\gamma \delta$ T cells are dysfunctional and are associated with lower risk of acquiring clinical episodes

To investigate the relationship between expression of TIM3 and cytokine and cytotoxic capacity, the functional

Table 1 The most parsimonius model for negative binomial regression for TIM3 + CD16+ TEMRA $\gamma \delta$ T cell frequency and molFOl

\begin{tabular}{|c|c|c|c|c|}
\hline P. falciparum force of infection & IRR & $P$ & $95 \% \mathrm{Cl}$ & \\
\hline PQ treatment arm & 0.74 & 0.035 & 0.57 & 0.98 \\
\hline$\%$ TIM3+ CD16+ TEMRA $\gamma \delta$ T cell (power transformed) & 1.40 & 0.027 & 1.04 & 1.88 \\
\hline $\mathrm{Hb}$ at sampling & 0.85 & $<0.001$ & 0.77 & 0.93 \\
\hline Recent $P$. falciparum ( $P$. falciparum infection at enrollment) & 1.85 & $<0.001$ & 1.39 & 2.46 \\
\hline
\end{tabular}



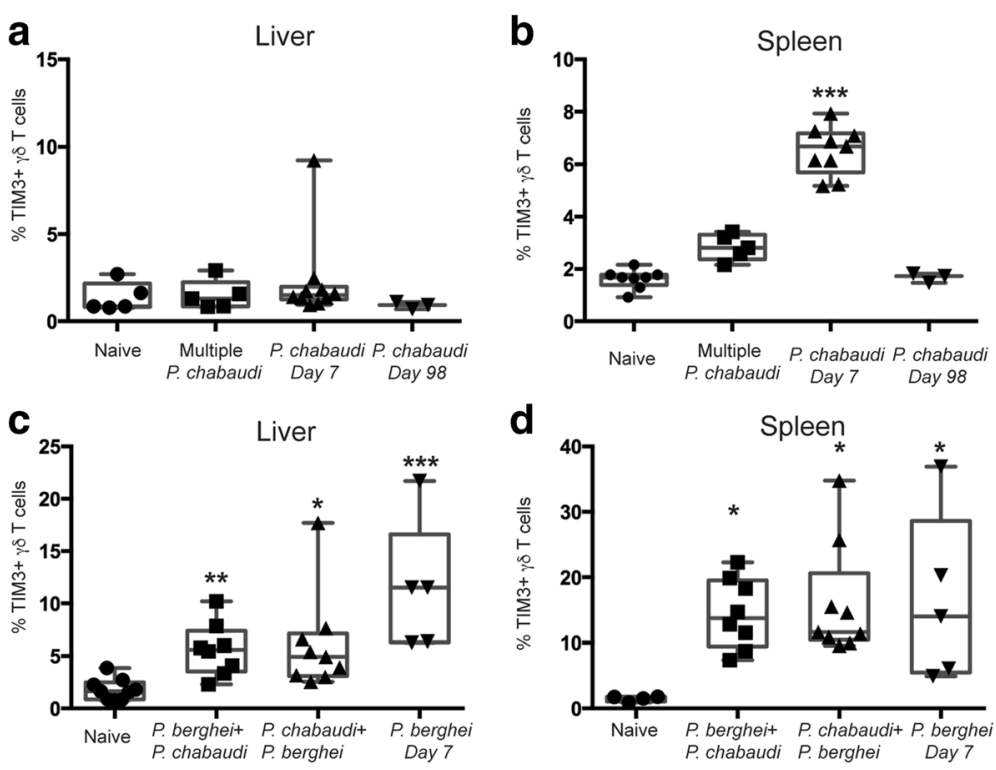

Fig. 3 Infection and exposure to multiple malaria species are associated with upregulated TIM3 expression. C57BL/6 mice were infected with $P$. chabaudi and then drug-treated with chloroquine and pyrimethamine. (a) Liver lymphocytes and (b) splenocytes were stained for TIM3 expression on day 7 following completion of drug cure to assess the percentage of TIM $3+\gamma \delta T$ cells from mice which received either three sequential P. chabaudi infections (Multiple P. chabaudi, $n=5$ ), single $P$. chabaudi infection ( $P$. chabaudi Day $7, n=9$ ), or single $P$. chabaudi infection 98 days prior to assessment ( $P$. chabaudi Day $98, n=3$ ). C57BL/6 mice were infected with either $P$. chabaudi or $P$. berghei and then drug-treated. (c) Liver lymphocytes and (d) splenocytes were assessed for TIM $3+\gamma \delta T$ cells on day 7 following end of drug cure from mice which received either $P$. chabaudi infection followed by $P$. berghei infection (P. chabaudi $+P$. berghei, $n=8)$, $P$. berghei infection followed by $P$. chabaudi infection $(P$. berghei + $P$. chabaudi, $n=9$ ), or single $P$. berghei infection ( $P$. berghei Day $7, n=5$ ). The data represent two independent experiments. Statistical analysis was performed using Kruskal-Wallis tests with Dunn's post-test; comparison to naive mice. ${ }^{*} P<0.05,{ }^{* *} P<0.01,{ }^{* * *} P<0.001$

capacity of TIM $3+\gamma \delta$ T cells was determined in a subset of children where cells were available. Cytokine production and cytotoxic activity was assessed following stimulation with iRBCs or the phosphoantigen isopentenyl pyrophosphate (IPP). The predominant subsets that produce either IFN- $\gamma$ or TNF- $\alpha$ following these stimulation conditions were TCM and TEM, collectively here referred to as memory $\gamma \delta \mathrm{T}$ cells, whereas cytotoxic activity was mainly observed in TEM and TEMRA subsets. The overall magnitude of the responses of all $\gamma \delta$ T cells following background subtraction is summarized in Additional file 5: Table S2.

Children were divided into responders and nonresponders. A positive response was determined as cytokine production and cytotoxic activity following stimulation, which was twice above background and with a frequency of $\geq 0.1 \%$ positive $\gamma \delta$ T cells of all $\gamma \delta$ T cells or $\geq 0.5 \%$ positive $\gamma \delta$ T cells of $\gamma \delta \mathrm{T}$ cell subsets following subtraction of background. Representative FACS plots of responses are presented in Additional file 6: Figure S4. We found that children in which $\gamma \delta$ T cells did not produce cytokine (non-responders, $n=30$ ) or lacked cytotoxic activity $(n=33)$ following stimulation with iRBCs had a significantly higher proportion of TIM $3+\gamma \delta$ T cells compared to individuals where $\gamma \delta \mathrm{T}$ cells responded to antigenic stimuli (Fig. 4a and b; cytokine responders $n=$ 21, $P=0.0005$ and CD107a responders $n=31, P=0.015$ ). Comparable results were observed with cytokine production following IPP stimulation, but not with cytolytic $\gamma \delta \mathrm{T}$ cells (Fig. 4e and f). Further analysis assessing TIM3 expression of all IFN- $\gamma+$, TNF- $\alpha+$, and CD107a $+\gamma \delta$ T cells following stimulation with iRBCs (Fig. 4c and d) or IPP (Fig. 4g and $\mathrm{h}$ ) revealed that effectively all cells that produce cytokines and exerted cytotoxic activity do not express TIM3 (Additional file 6: Figure S4). Collectively, this demonstrates that TIM $3+\gamma \delta$ T cells do not produce IFN$\gamma$ or TNF- $\alpha$ and lack cytotoxic activity in response to iRBC or phosphoantigen. Thus, the presence of these cells in the periphery of individuals may significantly affect their ability to respond to pathogens.

To further understand the relevance of these processes for the development of symptomatic malaria, associations between TIM3 expression on $\gamma \delta$ T cells and the occurrence and incidence of clinical malaria during the follow-up period were explored. Significantly higher frequencies of CD16+ TIM3+ TEMRA $\gamma \delta \mathrm{T}$ cells were found in individuals who only experienced an asymptomatic infection $(n=70)$ compared to children who had at least one clinical episode (Fig. $5, n=50, P=0.022$ ). In addition in a proportional hazards model adjusting for 

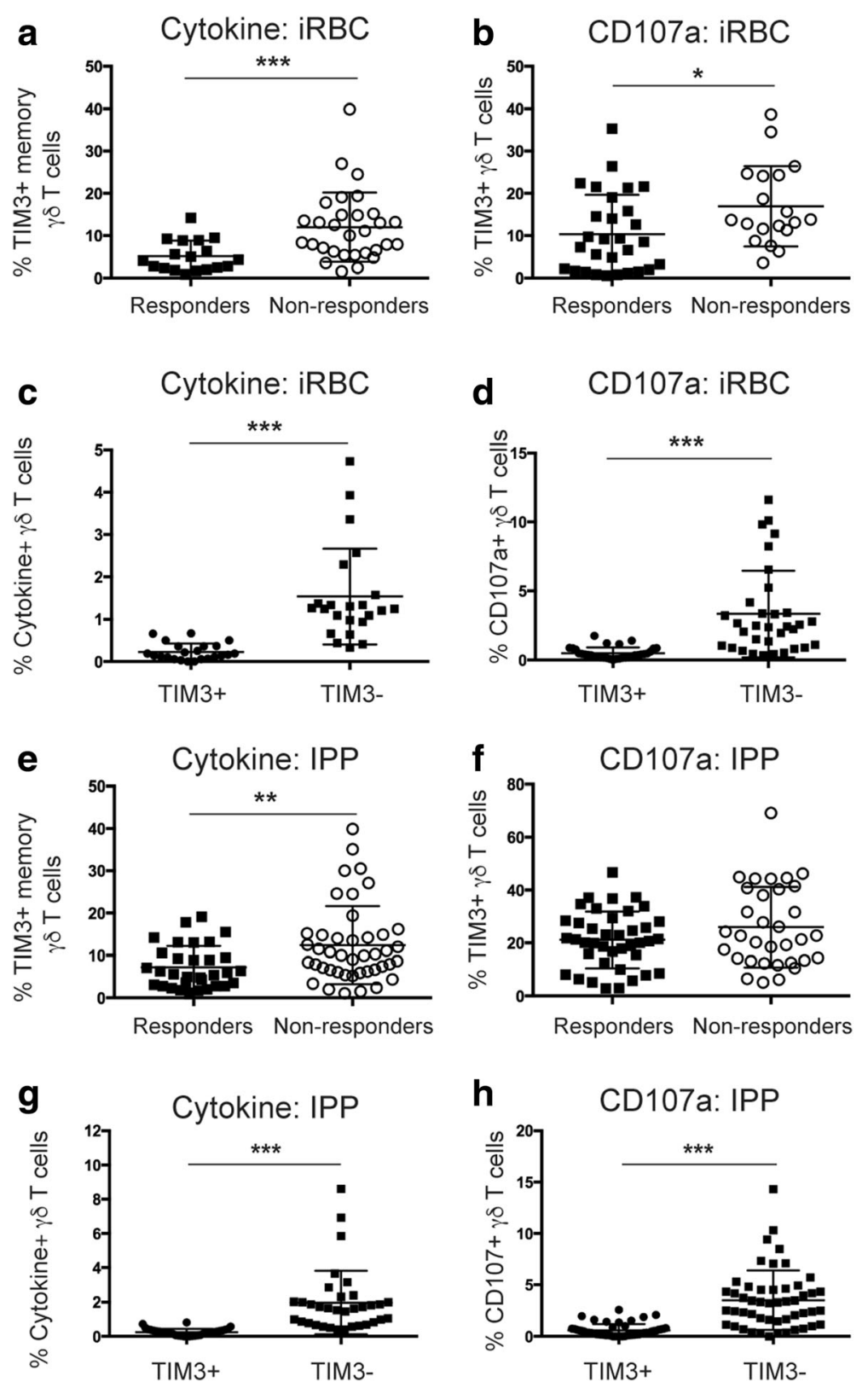

Fig. 4 TIM $3+\gamma \delta$ T cells are functionally inactive following stimulation with iRBCs and IPP. PBMCs from individuals living in malaria endemic areas were stimulated with iRBCs and then surface stained for TIM3 expression. Frequency of TIM3 $+\gamma \delta \mathrm{T}$ cells in (a) and (e) cytokine responders and non-responders and $(\mathbf{b})$ and $(\mathbf{f})$ in individuals with or without cytotoxically active $\gamma \delta T$ cells after stimulation with iRBC or IPP (responders; filled squares and non-responders; open circles). Comparison of TIM3 expression by (c) and (g) cytokine-producing $\gamma \delta$ T cells and (d) and (h) cytotoxic үठ T cells (TIM3+; filled circles and TIM3-; filled squares) in iRBC- or IPP-responding individuals. Statistical analysis was performed using (a, b, e, and f) Mann-Whitney tests and (c, d, $\mathbf{g}$, and $\mathbf{h}$ ) Wilcoxon matched pairs signed-rank test. ${ }^{*} P<0.05,{ }^{*} P<0.01,{ }^{* * *} P<0.001$

other covariates, the frequency of the CD16+ TIM3+ TEMRA $\gamma \delta \mathrm{T}$ cells was also associated with a longer time to first clinical episode (Table 2 and Additional file 7: Table S3, hazard ratio: $0.54,95 \%$ CI: $0.30-0.95, P=$ $0.032)$. Together these results indicate that the presence of CD16+ TIM3+ TEMRA $\gamma \delta$ T cells is a predictor of favorable disease outcome.
TIM3 expression by $\gamma \delta$ T cells is induced by proinflammatory cytokines and phosphoantigens

During Plasmodium infection a range of cytokines are induced which are associated with both protective responses as well as clinical outcomes and are also important for either a Th1 or Th2 response [62]. To determine if parasitespecific stimuli or specific cytokines related to malaria 


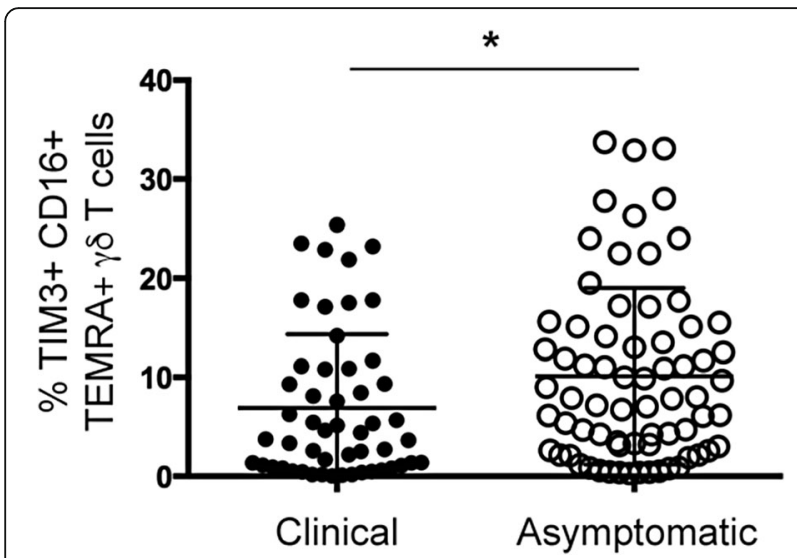

Fig. 5 Children who experience a clinical episode during follow-up have decreased frequency of TIM3+ CD16+ TEMRA $\gamma \delta$ T cells. Frequency of TIM3+ CD16+ TEMRA $\gamma \delta$ T cells in children with a clinical episode (filled circles; $n=50$ ) versus children with asymptomatic infection (open circles; $n=72$ ) during follow-up. Statistical analysis was performed using Mann-Whitney tests. ${ }^{*} P<0.05$

infection induce TIM3 expression on $\gamma \delta$ T cells, we stimulated PBMCs from healthy individuals in vitro with cytokines (IL-6, IL-1 $\beta$, TNF- $\alpha$, IL-12/IL-18, IL-4, and IFN- $\gamma$ ), IPP, iRBCs, or LPS for $24 \mathrm{~h}$. TIM3 was detected on the surface of $\gamma \delta$ T cells only in the presence of IPP and IL12/18 (Fig. 6a). Furthermore, IL-18 alone was unable to upregulate TIM3, but it augmented IL-12-induced TIM3 expression (Fig. 6b). As only IL-12/IL-18 induced TIM3 expression on $\gamma \delta$ T cells, the plasma levels of these TIM3inducing cytokines were investigated in the PNG children. Interestingly, plasma IL-18 levels were correlated with TIM3 expression (Fig. 6c; $r=0.30, P=0.0005$ ). This correlation remained significant in recently $P$. falciparuminfected children (Fig. 6d; $r=0.44, P=0.0009$ ) and in multivariable analyses (Table 3 and Additional file 8: Table S4, coefficient $0.03,95 \% \mathrm{CI}: 0.009-0.04, P=0.002$ ), whereas this association was not observed in non-P. falciparum-infected children (Fig. 6e; $r=0.096, P=0.41$ ), suggesting that IL-18 levels are driven by $P$. falciparum infection. In contrast, plasma IL-12 levels were undetectable in the majority of children at this time point.

\section{Discussion}

The significant contribution of $\gamma \delta \mathrm{T}$ cells to the overall immunity during infection and cancer is increasingly appreciated. Although recent efforts to utilize $\gamma \delta \mathrm{T}$ cells as immunotherapy effector cells have produced promising results [63], it is evident that a more comprehensive

Table 2 The most parsimonius model for proportional hazard model for TIM3+ CD16+ TEMRA $\gamma \delta$ T cell frequency and time to first clinical malaria episode

\begin{tabular}{|c|c|c|c|c|}
\hline & Hazard ratio & $P>z$ & $95 \% \mathrm{Cl}$ & \\
\hline TIM3+CD16+ TEMRA $\gamma \delta$ T cells & 0.54 & 0.032 & 0.30 & 0.95 \\
\hline
\end{tabular}

understanding of the biology related to immunoregulation of these cells is required to overcome the demonstrated induction of anergy and exhaustion upon repeat exposure to antigens [64, 65]. Our data demonstrated that in an infectious disease setting with continuous exposure to malaria, TIM3 expression becomes upregulated on $\gamma \delta \mathrm{T}$ cells, and this process is controlled by environmental cues provided by the host immune response. IFN- $\gamma$, TNF- $\alpha$, and cytotoxic activity were found to be absent in TIM3 $+\gamma \delta$ T cells upon re-stimulation with malaria antigens, and increased frequencies of these cells were associated with reduced risk of clinical malaria.

Although $P$. vivax is considered less virulent than $P$. falciparum, $P$. vivax is still a major cause of morbidity in endemic areas. Nevertheless, substantial differences in immunity to the two species have been noted, in particular in regard to naturally acquired immunity, where immunity to $P$. falciparum is slower to develop than immunity to $P$. vivax [66]. Few studies have compared innate responses and cytokine profiles between these species, though dissimilarities are plausible considering the distinct naturally acquired immunity patterns. We observed that recent infection with either $P$. vivax or $P$. falciparum affected the frequency of TIM $3+\gamma \delta$ T cells. However, the extent of TIM3 upregulation was different depending on the infective species. CD4+ T cells upregulate TIM3 following extended stimulation with IL-12 [67]. Similarly, we also found that IL-12/IL-18 can promote $\gamma \delta$ T cell upregulation of TIM3 in vitro where IL18 plays an auxiliary role. While both Plasmodium species are associated with increases in IL-12 production during acute infection, P. falciparum infection has been demonstrated to result in higher plasma IL-12 levels during convalescence $[68,69]$. In the current cohort IL12 was undetectable in the plasma, which is likely due to the absence of active infection for 28-30 days preceding the time point for PBMC collection. However, IL-18 plasma levels were readily detectable and were associated with TIM3 expression in P. falciparum-infected children at enrollment. Thus, dissimilar cytokine profiles and concentration levels at the time of infection may contribute to the difference in TIM $3+\gamma \delta$ T cell frequencies observed between children recently infected with $P$. vivax and $P$. falciparum. Notably, IL-12/IL-18 can also induce IFN- $\gamma$ production by $\gamma \delta$ T cells. However, the effect of IL-12/IL-18 on TIM3 induction by $\gamma \delta$ T cells may be dose-dependent, as was previously shown for TIM3 expression on CD4+ T cells [67]. Thus, early production of IL-12/IL-18 may promote IFN- $\gamma$ production, whereas accumulation of these cytokines in the plasma may induce $\gamma \delta$ T cells to upregulate TIM3. Furthermore, while no association was observed between IL-18 plasma levels in children who were not infected with $P$. falciparum 


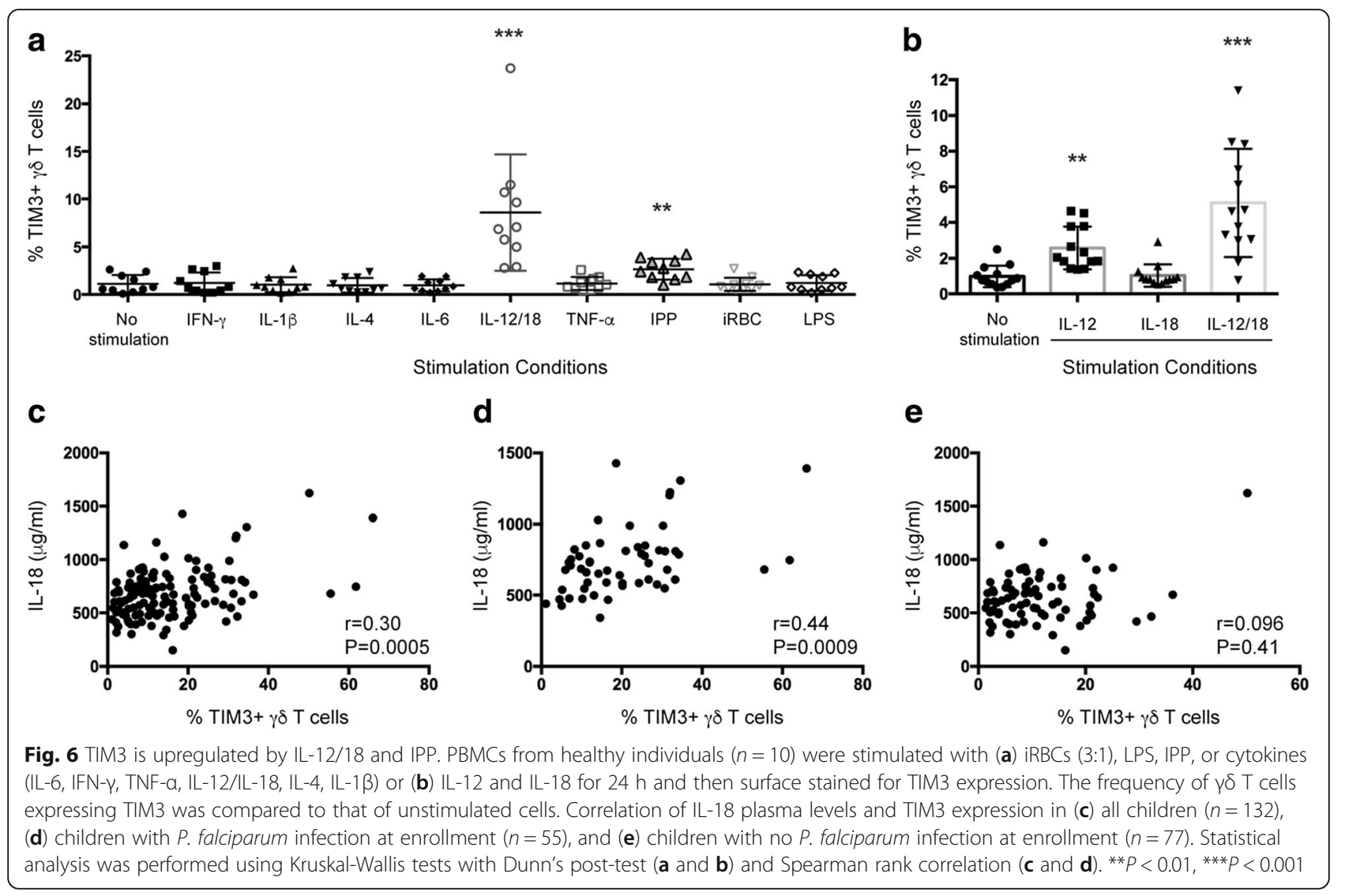

and TIM3 expression, these children still have an increased population of TIM $3+\gamma \delta \mathrm{T}$ cells. It is possible that phosphoantigen contributes to the observed TIM3 expression in these children, as IPP was also observed to induce TIM3 expression, albeit at lower frequency. However this remains to be determined.

Experimental mice infected with different Plasmodium species resulted in significant TIM3 upregulation, and TIM3 $+\gamma \delta$ T cells remained detectable after resolution of infection. Comparable findings were observed in the PNG children where TIM3 expression was associated with molFOI, thus suggesting that exposure to distinct parasites is important for induction of TIM3 during repeated exposure. Cytokine responses to malaria have been reported to be influenced by the immune status of the host $[70,71]$. It is possible that the differences in cytokine profiles resulting from re-infection with the same parasite among immune hosts versus infection with a new clone or species may affect TIM3 expression in the innate cell compartment.

Table 3 The most parsimonius model for general linear model of TIM3 $+\gamma \delta$ T cell frequency with IL-18 levels in children with recent $P$. falciparum infection

\begin{tabular}{lclcl}
\hline & Coefficient & $P$ & $95 \% \mathrm{Cl}$ & \\
\hline $\mathrm{LL}-18(\mu \mathrm{g} / \mathrm{ml})$ & 0.03 & 0.002 & 0.009 & 0.04 \\
\hline
\end{tabular}

Continuous exposure to malaria is correlated with immunity to symptomatic disease and is likely to involve both antiparasitic mechanisms and regulation of cytokines implicated in immunopathogenesis [72]. $\gamma \delta \mathrm{T}$ cells play a protective role as a major IFN- $\gamma$ producer during malaria infection [73] but are also a major source of cytokines and chemokines associated with disease [29]. Typically, $\mathrm{V} \gamma 9+$ $\mathrm{V} \delta 2+\mathrm{T}$ cells are considered to be the malaria-antigen responsive cells and also represent the majority of $\gamma \delta$ T cells in peripheral blood $[31,74]$. However, the functional roles for $\gamma \delta$ T cells in general are continuously expanding, indicating that the contribution of other subsets of $\gamma \delta$ T cells to both malaria immunity and immunopathogenesis may not be completely appreciated. Therefore, in contrast with the previous studies, we investigated TIM3 expression on the total $\gamma \delta$ T cell population without distinguishing subsets based on TCR restriction. In the current study, we found that the TIM $3+\gamma \delta$ T cells from malaria-exposed individuals were effectively unresponsive to stimulation in vitro. The cells produced minimal IFN- $\gamma$ and TNF- $\alpha$ and demonstrated low cytotoxic activity in response to iRBCs or phosphoantigen, thus indicating that these cells were functionally impaired. Interestingly, we observed that TIM3 was predominately expressed by CD16+ TEMRA $\gamma \delta \mathrm{T}$ cells. Our study is aligned with recent findings suggesting that dysfunctional CD16+ $\gamma \delta$ T cells emerge in 
response to malaria exposure [75]. While CD16 upregulation is most likely a consequence of prior TCR activation [76], expression of CD16 alone does not explain why these cells are impaired. Here we identified TIM3 as a potential receptor responsible for the $\gamma \delta \mathrm{T}$ cell impairment associated with malaria infection.

It is worth noting that the CD16+ TEMRA $\gamma \delta \mathrm{T}$ cell subset is reported to be unresponsive to phosphoantigen stimulation [61]. Instead CD16 allows $\gamma \delta \mathrm{T}$ cells to recognize opsonized targets. Farrington et al. (2016) proposed that accumulation of CD16+ cells represents a population which is preferentially stimulated through this receptor independently of the TCR [75]. However, signaling through CD16 results in both TNF- $\alpha$ and IFN$\gamma$ production $[61,76]$. Given that TNF- $\alpha$ is a pyrogenic cytokine that significantly contributes towards malaria febrile disease [77, 78], it indicates that inhibition of CD16+ TEMRA $\gamma \delta \mathrm{T}$ cells may be necessary to limit immunopathogenesis in the host. Notably, this study identifies specifically that the TIM3+ CD16+ TEMRA $\gamma \delta$ $\mathrm{T}$ cell population was associated with reduced clinical incidence risk, which supports the concept that regulation of highly specialized subsets is important for reducing clinical malaria symptoms. Thus, increased TIM3 expression on this population was associated with less risk of febrile malaria and was associated with asymptomatic infections. While TIM3 may not directly inhibit CD16 signaling, a functional linkage between CD16 and TCR signaling has been reported [79]. In $\alpha \beta$ T cells, TIM3 inhibition of TCR signaling is regulated by Bat3 interaction potentially through binding of catalytically active Lck [80]. Thus, TIM3 inhibition of the TCR may also affect the CD16-dependent response in this $\gamma \delta \mathrm{T}$ cell population, although this remains to be determined.

While we detected TIM $3+\gamma \delta$ T cells in the mouse model, in vivo assessment of their relative contribution to disease outcome using either a TIM3 knock-out mouse model or TIM3 depletion or blocking is hampered by the fact that TIM3 is known to be expressed by several different cell populations. These approaches would result in the inability to specifically assign effects on disease outcome to TIM $3+\gamma \delta$ T cells. Thus, a conditional knock-out mouse model would be required to address this. Furthermore, adoptive transfer of TIM $3+\gamma \delta$ T cells is potentially confounded by the presence of bound antibody, which may interfere with endogenous ligand interaction. Consequently, experimentally defining the role of TIM $3+\gamma \delta \mathrm{T}$ cells for malaria disease outcome in vivo still remains unresolved.

\section{Conclusions}

In conclusion, this study demonstrates the effect of continuous malaria exposure in shaping the innate immune response. The findings further emphasize the importance of regulating immune cells as part of clinical immunity to malaria. However, they also demonstrate that the inhibitory receptor TIM3 is an important regulatory component in $\gamma \delta \mathrm{T}$ cell biology and may have implications for disease management of malaria as well as $\gamma \delta \mathrm{T}$ cell immunotherapy in general.

\section{Additional files}

Additional file 1: Figure S1. Schematic of single and multiple infections with $P$. berghei and/or $P$. chabaudi. C57BL/6 mice were infected with (A) $P$. chabaudi three consecutive times with drug treatment between infections, (B) P berghei only, P. chabaudi followed by drug treatment and then $P$. berghei infection or vice versa, or (C) $P$. chabaudi to establish chronic infections followed by drug treatment. (TIF $1009 \mathrm{~kb}$ )

Additional file 2: Figure S2. Gating strategy used to determine $\gamma \delta T$ cell memory populations and TIM3 expression by $\gamma \delta \mathrm{T}$ cells in both PBMC samples and mice. (TIF $1730 \mathrm{~kb}$ )

Additional file 3: Figure S3. PD1 expression by $\gamma \delta T$ cells is absent. PBMCs from individuals living in malaria endemic areas and healthy controls (HC) were surface stained for TIM3 and PD1 expression. (A) Frequency of $\gamma \delta \mathrm{T}$ cells expressing TIM3 or PD1 in individuals living in malaria endemic areas. (B) Frequency of CD3 $+\gamma \delta T C R-$ cells expressing PD1 in HC and individuals living in malaria endemic areas. Statistical analysis was performed using Paired $t$ tests (A) or Mann-Whitney tests (B). ***P $<0.001$. (TIF $1245 \mathrm{~kb}$ )

Additional file 4: Table S1. Negative binomial regression for TIM3 + CD16+ TEMRA $\gamma \delta$ T cell frequency and molFOI. (DOC 35 kb)

Additional file 5. Table S2. Frequency of $\gamma \delta T$ cell responses following background subtraction. (DOC $30 \mathrm{~kb}$ )

Additional file 6: Figure S4. TIM $3+\gamma \delta$ T cells are functionally impaired following stimulation with iRBCs and IPP. PBMCs from individuals living in malaria endemic areas were stimulated with either IRBCs or IPP and then surface stained for TIM3 expression. FACS plots representing frequency of TIM3 expression on IFN- $\gamma$, TNF-a, and CD107a producing $\gamma \delta$ T cells following stimulation with iRBCs and URBCs (top panel) or IPP and no stimulation (bottom panel). (TIF $1308 \mathrm{~kb}$ )

Additional file 7: Table S3. Proportional hazard model for TIM3+ CD16 + TEMRA $\gamma \delta T$ cell frequency and time to first clinical malaria episode. (DOC $35 \mathrm{~kb}$ )

Additional file 8: Table S4. General linear model of TIM3 $+\gamma \delta \mathrm{T}$ cell frequency with $\mathrm{IL}-18$ levels in children with recent $P$. falciparum infection. (DOC $33 \mathrm{~kb}$ )

\section{Abbreviations}

CQ: Chloroquine; DOT: Directly observed treatment; HC: Healthy control; IPP: Isopentenyl pyrophosphate; iRBC: Infected red blood cell; mol FOI: Molecular force of infection; PNG: Papua New Guinea; PQ: Primaquine; TIM3: T-cell immunoglobulin domain and mucin domain 3; URBC: Uninfected red blood cell

\section{Acknowledgements}

We wish to thank the children and guardians for their participation in the study. We would like to acknowledge the staff at the Albinama Health Centre and Papua New Guinea Institute of Medical Research staff for their support and assistance. We acknowledge the efforts of the PNG Institute of Medical Research - Maprik field, administration, microscopy, and laboratory staff, in particular, Benson Kiniboro, Lawrence Rare, Danga Mark, and Heather Huaupe. We thank Ingrid Felger, Natalie E. Hofmann, and Rahel Wampfler at Swiss TPH as well as Andreea Waltmann and Jessica Brewster at Walter and Eliza Hall Institute of Medical Research (WEHI) for the molecular parasitology. We thank Amandine B. Carmagnac and Liana Mackiewicz at WEHI for technical assistance. 


\section{Funding}

This work was supported by NHMRC grant APP106722 and the International Centers of Excellence in Malaria Research (grant U19 Al089686). This work was made possible through Victorian State Government Operational Infrastructure Support and Australian Government NHMRC IRIISS. LJ.R was supported by a National Health and Medical Research Council (NHMRC) Early Career Fellowship \#1016443. IM is supported by an NHMRC Senior Research Fellowship (\#1043345). The funders had no role in study design, data collection and analysis, decision to publish, or preparation of the manuscript.

\section{Availability of data and materials}

The datasets used and/or analyzed during the current study are available from the corresponding author on reasonable request.

\section{Authors' contributions}

LS critically reviewed the manuscript and study; LII designed and conducted experiments and critically reviewed the manuscript; SK analyzed data and critically reviewed the manuscript; LJR conducted fieldwork and sample collection, isolated human PBMCs, provided samples and clinical and parasitological data, and critically reviewed the manuscript; QYT conducted experiments and provided technical assistance; DPP conducted experiments, acquired data, and critically reviewed the manuscript; IB conducted fieldwork and provided samples and clinical data; DLH provided technical assistance; PMS provided samples; DSH critically reviewed the manuscript and study; IM critically reviewed the manuscript and study; EME designed and conducted experiments, analyzed data, acquired data, and wrote the manuscript. All authors read and approved the final manuscript.

\section{Competing interests}

The authors declare that they have no competing interests.

\section{Consent for publication}

\section{Not applicable.}

\section{Study approval}

Parents of children enrolled in the study provided written informed consent. The study received ethical clearance from the PNG IMR Institutional Review Board (0908 and 0909), the PNG Medical Advisory Committee (09.11), and the Walter and Eliza Hall Institute (WEHI) Committee on Human Research (09/06) and was conducted in full accordance with the Declaration of Helsinki. Use of human red blood cells was approved by the WEHI Human Research Ethics Committee (86/17) and an Australian Red Cross Blood Service Agreement (11-09VIC-01). All animal experiments were approved by the WEHI Animal Ethics Committee (2013.013).

\section{Publisher's Note}

Springer Nature remains neutral with regard to jurisdictional claims in published maps and institutional affiliations.

\section{Author details}

${ }^{1}$ Walter and Eliza Hall Institute of Medical Research, Division of Population Health and Immunity, Melbourne, VIC 3052, Australia. ${ }^{2}$ Australian Institute of Tropical Health and Medicine, James Cook University, Townsville, QLD 4811 Australia. ${ }^{3}$ Department of Medical Biology, The University of Melbourne, Melbourne, VIC 3052, Australia. ${ }^{4}$ Papua New Guinea Institute of Medical Research, Goroka and Madang, Papua New Guinea. ${ }^{5}$ Burnet Institute, Melbourne, VIC 3004, Australia. ${ }^{6}$ Monash Institute of Pharmaceutical Sciences, Monash University, Melbourne, VIC 3052, Australia. ${ }^{7}$ Department of Anatomy and Neuroscience, The University of Melbourne, Melbourne, VIC 3010, Australia. ${ }^{8}$ School of Veterinary and Biomedical Sciences, James Cook University, Townsville, QLD 4811, Australia. ${ }^{9} T h e$ Walter and Eliza Hall Institute of Medical Research, $1 \mathrm{G}$ Royal Parade, Melbourne, VIC 3052, Australia.
}

Received: 3 December 2016 Accepted: 22 May 2017

Published online: 15 June 2017

\section{References}

1. Pentcheva-Hoang T, Corse E, Allison JP. Negative regulators of T-cell activation: potential targets for therapeutic intervention in cancer, autoimmune disease, and persistent infections. Immunol Rev. 2009; 229(1):67-87.
2. Anderson AC. Tim-3: an emerging target in the cancer immunotherapy landscape. Cancer Immunol Res. 2014;2(5):393-8.

3. Day CL, Kaufmann DE, Kiepiela P, Brown JA, Moodley ES, Reddy S, Mackey EW, Miller JD, Leslie AJ, DePierres C, et al. PD-1 expression on HIV-specific T cells is associated with T-cell exhaustion and disease progression. Nature. 2006:443(7109):350-4.

4. Jones RB, Ndhlovu LC, Barbour JD, Sheth PM, Jha AR, Long BR, Wong JC, Satkunarajah M, Schweneker M, Chapman JM, et al. Tim-3 expression defines a novel population of dysfunctional T cells with highly elevated frequencies in progressive HIV-1 infection. J Exp Med. 2008;205(12):2763-79.

5. Peng G, Li S, Wu W, Tan X, Chen Y, Chen Z. PD-1 upregulation is associated with HBV-specific T cell dysfunction in chronic hepatitis B patients. Mol Immunol. 2008:45(4):963-70

6. Sakhdari A, Mujib S, Vali B, Yue FY, MacParland S, Clayton K, Jones RB, Liu J, Lee EY, Benko $E$, et al. Tim-3 negatively regulates cytotoxicity in exhausted CD8+ T cells in HIV infection. PLoS ONE. 2012;7(7), e40146.

7. Sakuishi K, Apetoh L, Sullivan JM, Blazar BR, Kuchroo VK, Anderson AC. Targeting Tim-3 and PD-1 pathways to reverse T cell exhaustion and restore anti-tumor immunity. J Exp Med. 2010;207(10):2187-94.

8. Singh A, Mohan A, Dey AB, Mitra DK. Inhibiting the programmed death 1 pathway rescues Mycobacterium tuberculosis-specific interferon gammaproducing T cells from apoptosis in patients with pulmonary tuberculosis. J Infect Dis. 2013;208(4):603-15.

9. Butler NS, Moebius J, Pewe LL, Traore B, Doumbo OK, Tygrett LT, Waldschmidt TJ, Crompton PD, Harty JT. Therapeutic blockade of PD-L1 and LAG-3 rapidly clears established blood-stage Plasmodium infection. Nat Immunol. 2012;13(2):188-95.

10. Hafalla JC, Claser C, Couper KN, Grau GE, Renia L, de Souza JB, Riley EM. The CTLA-4 and PD-1/PD-L1 inhibitory pathways independently regulate host resistance to Plasmodium-induced acute immune pathology. PLoS Pathog. 2012;8(2), e1002504

11. Horne-Debets JM, Faleiro R, Karunarathne DS, Liu XQ, Lineburg KE, Poh CM, Grotenbreg GM, Hill GR, MacDonald KP, Good MF, et al. PD-1 dependent exhaustion of CD8+ T cells drives chronic malaria. Cell Rep. 2013;5(5):1204-13.

12. Illingworth J, Butler NS, Roetynck S, Mwacharo J, Pierce SK, Bejon P, Crompton PD, Marsh K, Ndungu FM. Chronic exposure to Plasmodium falciparum is associated with phenotypic evidence of $B$ and $T$ cell exhaustion. J Immunol. 2013;190(3):1038-47.

13. Hou N, Zou Y, Piao X, Liu S, Wang L, Li S, Chen Q. T-Cell immunoglobulinand mucin-domain-containing molecule 3 signaling blockade improves cellmediated immunity against malaria. J Infect Dis. 2016;214(10):1547-56.

14. Elloso MM, Wallace M, Manning DD, Weidanz WP. The effects of interleukin15 on human gammadelta T cell responses to Plasmodium falciparum in vitro. Immunol Lett. 1998;64(2-3):125-32.

15. Ladel CH, Blum C, Dreher A, Reifenberg K, Kaufmann SH. Protective role of gamma/delta T cells and alpha/beta T cells in tuberculosis. Eur J Immunol. 1995;25(10):2877-81.

16. Rosat JP, MacDonald HR, Louis JA. A role for gamma delta + T cells during experimental infection of mice with Leishmania major. J Immunol. 1993; 150(2):550-5.

17. Tsuji M, Mombaerts $P$, Lefrancois L, Nussenzweig RS, Zavala F, Tonegawa S. Gamma delta $T$ cells contribute to immunity against the liver stages of malaria in alpha beta T-cell-deficient mice. Proc Natl Acad Sci U S A. 1994; 91(1):345-9

18. Tsukaguchi K, Balaji KN, Boom WH. CD4+ alpha beta T cell and gamma delta T cell responses to Mycobacterium tuberculosis. Similarities and differences in Ag recognition, cytotoxic effector function, and cytokine production. J Immunol. 1995;154(4):1786-96.

19. van der Heyde HC, Elloso MM, Chang WL, Kaplan M, Manning DD, Weidanz WP. Gamma delta T cells function in cell-mediated immunity to acute blood-stage Plasmodium chabaudi adami malaria. J Immunol. 1995;154(8): 3985-90.

20. Guenot M, Loizon S, Howard J, Costa G, Baker DA, Mohabeer SY, TroyeBlomberg M, Moreau JF, Dechanet-Merville J, Mercereau-Puijalon O, et al. Phosphoantigen burst upon Plasmodium falciparum schizont rupture can distantly activate Vgamma9Vdelta2 T cells. Infect Immun. 2015;83(10):3816-24.

21. Inoue S, Niikura M, Mineo S, Kobayashi F. Roles of IFN-gamma and gammadelta $T$ cells in protective immunity against blood-stage malaria. Front Immunol. 2013;4:258.

22. Stanisic DI, Good MF. Examining cellular immune responses to inform development of a blood-stage malaria vaccine. Parasitology. 2016;143(2):208-23. 
23. Roestenberg M, McCall M, Hopman J, Wiersma J, Luty AJ, van Gemert GJ, van de Vegte-Bolmer M, van Schaijk B, Teelen K, Arens T, et al. Protection against a malaria challenge by sporozoite inoculation. N Engl J Med. 2009; 361(5):468-77

24. Weidanz WP, LaFleur G, Brown A, Burns Jr JM, Gramaglia I, van der Heyde HC. Gammadelta T cells but not NK cells are essential for ce IImediated immunity against Plasmodium chabaudi malaria. Infect Immun. 2010;78(10):4331-40.

25. D'Ombrain MC, Hansen DS, Simpson KM, Schofield L. gammadelta-T cells expressing NK receptors predominate over NK cells and conventional T cells in the innate IFN-gamma response to Plasmodium falciparum malaria. Eur J Immunol. 2007;37(7):1864-73.

26. Hensmann M, Kwiatkowski D. Cellular basis of early cytokine response to Plasmodium falciparum. Infect Immun. 2001;69(4):2364-71.

27. McCall MB, Sauerwein RW. Interferon-gamma - central mediator of protective immune responses against the pre-erythrocytic and blood stage of malaria. J Leukoc Biol. 2010;88(6):1131-43.

28. Robinson LJ, D'Ombrain MC, Stanisic DI, Taraika J, Bernard N, Richards JS, Beeson JG, Tavul L, Michon P, Mueller I, et al. Cellular tumor necrosis factor, gamma interferon, and interleukin- 6 responses as correlates of immunity and risk of clinical Plasmodium falciparum malaria in children from Papua New Guinea. Infect Immun. 2009;77(7):3033-43.

29. Stanisic DI, Cutts J, Eriksson E, Fowkes FJ, Rosanas-Urgell A, Siba P, Laman M, Davis TM, Manning L, Mueller I, et al. gammadelta T cells and CD14+ monocytes are predominant cellular sources of cytokines and chemokines associated with severe malaria. J Infect Dis. 2014;210(2):295-305.

30. Teirlinck AC, McCall MB, Roestenberg M, Scholzen A, Woestenenk R, de Mast Q, van der Ven AJ, Hermsen CC, Luty AJ, Sauerwein RW. Longevity and composition of cellular immune responses following experimental Plasmodium falciparum malaria infection in humans. PLoS Pathog. 2011;7(12), e1002389.

31. Costa G, Loizon S, Guenot M, Mocan I, Halary F, de Saint-Basile G, Pitard V, Dechanet-Merville J, Moreau JF, Troye-Blomberg M, et al. Control of Plasmodium falciparum erythrocytic cycle: gammadelta T cells target the red blood cell-invasive merozoites. Blood. 2011:118(26):6952-62.

32. Farouk SE, Mincheva-Nilsson L, Krensky AM, Dieli F, Troye-Blomberg M. Gamma delta T cells inhibit in vitro growth of the asexual blood stages of Plasmodium falciparum by a granule exocytosis-dependent cytotoxic pathway that requires granulysin. Eur J Immunol. 2004;34(8):2248-56.

33. Troye-Blomberg M, Worku S, Tangteerawatana P, Jamshaid R, Soderstrom K, Elghazali G, Moretta L, Hammarstrom M, Mincheva-Nilsson L. Human gamma delta T cells that inhibit the in vitro growth of the asexual blood stages of the Plasmodium falciparum parasite express cytolytic and proinflammatory molecules. Scand J Immunol. 1999;50(6):642-50.

34. Yanez DM, Batchelder J, van der Heyde HC, Manning DD, Weidanz WP. Gamma delta T-cell function in pathogenesis of cerebral malaria in mice infected with Plasmodium berghei ANKA. Infect Immun. 1999;67(1):446-8.

35. de Souza AJ, Kane LP. Immune regulation by the TIM gene family. Immunol Res. 2006;36(1-3):147-55.

36. Freeman GJ, Casasnovas JM, Umetsu DT, DeKruyff RH. TIM genes: a family of cell surface phosphatidylserine receptors that regulate innate and adaptive immunity. Immunol Rev. 2010;235(1):172-89.

37. Kane LP. T cell Ig and mucin domain proteins and immunity. J Immunol. 2010;184(6):2743-9.

38. Kuchroo VK, Umetsu DT, DeKruyff RH, Freeman GJ. The TIM gene family: emerging roles in immunity and disease. Nat Rev Immunol. 2003;3(6):454-62

39. Zhu C, Anderson AC, Schubart A, Xiong H, Imitola J, Khoury SJ, Zheng XX, Strom TB, Kuchroo VK. The Tim-3 ligand galectin-9 negatively regulates T helper type 1 immunity. Nat Immunol. 2005;6(12):1245-52.

40. Jin HT, Anderson AC, Tan WG, West EE, Ha SJ, Araki K, Freeman GJ, Kuchroo VK, Ahmed R. Cooperation of Tim-3 and PD-1 in CD8 T-cell exhaustion during chronic viral infection. Proc Natl Acad Sci U S A. 2010;107(33):14733-8

41. Takamura S, Tsuji-Kawahara S, Yagita H, Akiba H, Sakamoto M, Chikaishi T, Kato M, Miyazawa M. Premature terminal exhaustion of Friend virus-specific effector CD8+ T cells by rapid induction of multiple inhibitory receptors. J Immunol. 2010;184(9):4696-707.

42. Ndhlovu LC, Lopez-Verges S, Barbour JD, Jones RB, Jha AR, Long BR, Schoeffler EC, Fujita T, Nixon DF, Lanier LL. Tim-3 marks human natural killer cell maturation and suppresses cell-mediated cytotoxicity. Blood. 2012;119(16):3734-43.

43. Zhang Y, Ma CJ, Wang JM, Ji XJ, Wu XY, Jia ZS, Moorman JP, Yao ZQ. Tim-3 negatively regulates $\mathrm{IL}-12$ expression by monocytes in $\mathrm{HCV}$ infection. PLoS ONE. 2011;6(5), e19664
44. Zhang Y, Ma CJ, Wang JM, Ji XJ, Wu XY, Moorman JP, Yao ZQ. Tim-3 regulates pro- and anti-inflammatory cytokine expression in human CD14+ monocytes. J Leukoc Biol. 2012;91(2):189-96.

45. Xiao S, Liu J, Huang S, Lu F. Increased Gal-9 and Tim-3 expressions during liver damage in a murine malarial model. Parasitol Res. 2016;115(2):663-72.

46. Costa PA, Leoratti FM, Fiqueiredo MM, Tada MS, Pereira DB, Junqueira C, Soares IS, Barber DL, Gazzinelli RT, Antonelli LR. Induction of inhibitory receptors on T cells during Plasmodium vivax malaria impairs cytokine production. J Infect Dis. 2015;212(12):1999-2010.

47. Jagannathan P, Kim CC, Greenhouse B, Nankya F, Bowen K, Eccles-James I, Muhindo MK, Arinaitwe E, Tappero JW, Kamya MR, et al. Loss and dysfunction of Vdelta2(+) gammadelta T cells are associated with clinical tolerance to malaria. Sci Transl Med. 2014;6(251):251ra117.

48. Miko E, Szereday L, Barakonyi A, Jarkovich A, Varga P, Szekeres-Bartho J. Immunoactivation in preeclampsia: Vdelta2+ and regulatory $T$ cells during the inflammatory stage of disease. J Reprod Immunol. 2009;80(1-2):100-8.

49. Robinson LJ, Wampfler R, Betuela I, Karl S, White MT, Li Wai Suen CS, Hofmann NE, Kinboro B, Waltmann A, Brewster J, et al. Strategies for understanding and reducing the Plasmodium vivax and Plasmodium ovale hypnozoite reservoir in Papua New Guinean children: a randomised placebo-controlled trial and mathematical model. PLoS Med. 2015;12(10):e1001891.

50. Rosanas-Urgell A, Mueller D, Betuela I, Barnadas C, Iga J, Zimmerman PA, de Portillo HA, Siba P, Mueller I, Felger I. Comparison of diagnostic methods for the detection and quantification of the four sympatric Plasmodium species in field samples from Papua New Guinea. Malar J. 2010;9:361.

51. Wampfler R, Mwingira F, Javati S, Robinson L, Betuela I, Siba P, Beck HP, Mueller I, Felger I. Strategies for detection of Plasmodium species gametocytes. PLoS ONE. 2013;8(9), e76316.

52. loannidis LJ, Nie CQ, Ly A, Ryg-Cornejo V, Chiu CY, Hansen DS. Monocyte- and neutrophil-derived CXCL10 impairs efficient control of blood-stage malaria infection and promotes severe disease. J Immunol. 2016;196(3):1227-38.

53. Hommel M, Elliott SR, Soma V, Kelly G, Fowkes FJ, Chesson JM, Duffy MF, Bockhorst J, Avril M, Mueller I, et al. Evaluation of the antigenic diversity of placenta-binding Plasmodium falciparum variants and the antibody repertoire among pregnant women. Infect Immun. 2010;78(5):1963-78.

54. Falk N, Maire N, Sama W, Owusu-Agyei S, Smith T, Beck HP, Felger I. Comparison of PCR-RFLP and Genescan-based genotyping for analyzing infection dynamics of Plasmodium falciparum. Am J Trop Med Hyg. 2006; 74(6):944-50.

55. Mueller I, Schoepflin S, Smith TA, Benton KL, Bretscher MT, Lin E, Kiniboro B, Zimmerman PA, Speed TP, Siba P, et al. Force of infection is key to understanding the epidemiology of Plasmodium falciparum malaria in Papua New Guinean children. Proc Natl Acad Sci U S A. 2012;109(25):10030-5.

56. Schoepflin S, Valsangiacomo F, Lin E, Kiniboro B, Mueller I, Felger I. Comparison of Plasmodium falciparum allelic frequency distribution in different endemic settings by high-resolution genotyping. Malar J. 2009:8:250.

57. Dieli F, Poccia F, Lipp M, Sireci G, Caccamo N, Di Sano C, Salerno A. Differentiation of effector/memory Vdelta2 $\mathrm{T}$ cells and migratory routes in lymph nodes or inflammatory sites. J Exp Med. 2003;198(3):391-7.

58. Li Z, Jiao Y, Hu Y, Cui L, Chen D, Wu H, Zhang J, He W. Distortion of memory Vdelta2 gammadelta T cells contributes to immune dysfunction in chronic HIV infection. Cell Mol Immunol. 2015;12(5):604-14.

59. Odaira K, Kimura SN, Fujieda N, Kobayashi Y, Kambara K, Takahashi T, Izumi T, Matsushita H, Kakimi K. CD27(-)CD45(+) gammadelta T cells can be divided into two populations, CD27(-)CD45(int) and CD27(-)CD45(hi) with little proliferation potential. Biochem Biophys Res Commun. 2016;478(3):1298-303.

60. Pitard V, Roumanes D, Lafarge X, Couzi L, Garrigue I, Lafon ME, Merville P, Moreau JF, Dechanet-Merville J. Long-term expansion of effector/memory Vdelta2-gammadelta T cells is a specific blood signature of CMV infection. Blood. 2008;112(4):1317-24.

61. Angelini DF, Borsellino G, Poupot M, Diamantini A, Poupot R, Bernardi G, Poccia F, Fournie JJ, Battistini L. FcgammaRIII discriminates between 2 subsets of Vgamma9Vdelta2 effector cells with different responses and activation pathways. Blood. 2004;104(6):1801-7.

62. Angulo I, Fresno M. Cytokines in the pathogenesis of and protection against malaria. Clin Diagn Lab Immunol. 2002;9(6):1145-52.

63. Wu YL, Ding YP, Tanaka Y, Shen LW, Wei CH, Minato N, Zhang W. gammadelta T cells and their potential for immunotherapy. Int J Biol Sci. 2014;10(2):119-35.

64. Poupot M, Boissard F, Betous D, Bardouillet L, Fruchon S, L'Faqihi-Olive F, Pont F, Mekaouche M, Ingoure S, Sicard $\mathrm{H}$, et al. The PPARalpha pathway in Vgamma9Vdelta2 T cell anergy. Cell Mol Biol Lett. 2014;19(4):649-58. 
65. Sicard H, Ingoure S, Luciani B, Serraz C, Fournie JJ, Bonneville M, Tiollier J, Romagne $\mathrm{F}$. In vivo immunomanipulation of $\mathrm{V}$ gamma $9 \mathrm{~V}$ delta $2 \mathrm{~T}$ cells with a synthetic phosphoantigen in a preclinical nonhuman primate model. J Immunol. 2005:175(8):5471-80.

66. Mueller I, Galinski MR, Tsuboi T, Arevalo-Herrera M, Collins WE, King CL. Natural acquisition of immunity to Plasmodium vivax: epidemiological observations and potential targets. Adv Parasitol. 2013;81:77-131.

67. Yang ZZ, Grote DM, Ziesmer SC, Niki T, Hirashima M, Novak AJ, Witzig TE, Ansell SM. IL-12 upregulates TIM-3 expression and induces T cell exhaustion in patients with follicular B cell non-Hodgkin lymphoma. J Clin Invest. 2012; 122(4):1271-82.

68. Rodrigues-da-Silva RN, Lima-Junior Jda C, e Fonseca Bde P, Antas PR, Baldez A, Storer FL, Santos F, Banic DM, de Oliveira-Ferreira J. Alterations in cytokines and haematological parameters during the acute and convalescent phases of Plasmodium falciparum and Plasmodium vivax infections. Mem Inst Oswaldo Cruz. 2014;109(2):154-62.

69. Sarangi A, Mohapatra PC, Dalai RK, Sarangi AK. Serum IL-4, IL-12 and TNFalpha in malaria: a comparative study associating cytokine responses with severity of disease from the Coastal Districts of Odisha. J Parasit Dis. 2014; 38(2):143-7.

70. Rhee MS, Akanmori BD, Waterfall M, Riley EM. Changes in cytokine production associated with acquired immunity to Plasmodium falciparum malaria. Clin Exp Immunol. 2001;126(3):503-10.

71. Sinha S, Qidwai T, Kanchan K, Jha GN, Anand P, Pati SS, Mohanty S, Mishra SK, Tyagi PK, Sharma SK, et al. Distinct cytokine profiles define clinical immune response to falciparum malaria in regions of high or low disease transmission. Eur Cytokine Netw. 2010;21(4):232-40.

72. Schofield L, Grau GE. Immunological processes in malaria pathogenesis. Nat Rev Immunol. 2005;5(9):722-35.

73. D'Ombrain MC, Robinson L, Stanisic DI, Taraika J, Bernard N, Michon P, Mueller I, Schofield L. Association of early interferon-gamma production with immunity to clinical malaria: a longitudinal study among Papua New Guinean children. Clin Infect Dis. 2008;47(11):1380-7.

74. Elloso MM, van der Heyde HC, vande Waa JA, Manning DD, Weidanz WP. Inhibition of Plasmodium falciparum in vitro by human gamma delta T cells. J Immunol. 1994;153(3):1187-94.

75. Farrington LA, Jagannathan P, Mclntyre TI, Vance HM, Bowen K, Boyle MJ, Nankya F, Wamala S, Auma A, Nalubega $M$, et al. Frequent malaria drives progressive Vdelta2 T-cell loss, dysfunction, and CD16 up-regulation during early childhood. J Infect Dis. 2016;213(9):1483-90.

76. Lafont V, Liautard J, Liautard JP, Favero J. Production of TNF-alpha by human $\mathrm{V}$ gamma $9 \mathrm{~V}$ delta $2 \mathrm{~T}$ cells via engagement of $\mathrm{Fc}$ gamma RlllA, the low affinity type 3 receptor for the FC portion of IgG, expressed upon TCR activation by nonpeptidic antigen. J Immunol. 2001;166(12):7190-9.

77. Karunaweera ND, Wijesekera SK, Wanasekera D, Mendis KN, Carter R. The paroxysm of Plasmodium vivax malaria. Trends Parasitol. 2003;19(4):188-93.

78. McGuire W, D'Alessandro U, Stephens S, Olaleye BO, Langerock P, Greenwood BM, Kwiatkowski D. Levels of tumour necrosis factor and soluble TNF receptors during malaria fever episodes in the community. Trans R Soc Trop Med Hyg. 1998;92(1):50-3.

79. Braakman E, van de Winkel JG, van Krimpen BA, Jansze M, Bolhuis RL. CD16 on human gamma delta T lymphocytes: expression, function, and specificity for mouse IgG isotypes. Cell Immunol. 1992;143(1):97-107.

80. Rangachari M, Zhu C, Sakuishi K, Xiao S, Karman J, Chen A, Angin M, Wakeham A, Greenfield EA, Sobel RA, et al. Bat3 promotes T cell responses and autoimmunity by repressing Tim-3-mediated cell death and exhaustion. Nat Med. 2012;18(9):1394-400.

\section{Submit your next manuscript to BioMed Central and we will help you at every step:}

- We accept pre-submission inquiries

- Our selector tool helps you to find the most relevant journal

- We provide round the clock customer support

- Convenient online submission

- Thorough peer review

- Inclusion in PubMed and all major indexing services

- Maximum visibility for your research

Submit your manuscript at www.biomedcentral.com/submit 